\title{
CASE STUDY ON PERFORMANCE MONITORING AND STABILITY ANALYSIS OF BAISHIHU SUSPENSION BRIDGE AND SIDE SLOPE
}

\author{
Chihcheng CHEN ${ }^{1}$, Ban-Jwu SHIH ${ }^{1}$, Ching-Jiang JENG ${ }^{2^{*}}$ \\ ${ }^{1}$ Department of Civil and Disaster Prevention Engineering, National Taipei University of Technology, Taipei, Taiwan \\ ${ }^{2}$ Department of Landscape and Environmental Design, Huafan University, New Taipei City, Taiwan
}

Received 1 February 2021; accepted 13 July 2021

\begin{abstract}
The main structure of the Baishihu suspension bridge was connected to the anchor foundations by three main steel cables. The wooden pedestrian deck was fixed to the main steel cables using steel beams and was stabilized by two stabilizing cables. The stabilizing cables and bridge body were joined by 44 steel connecting rods. Therefore, the slope stability at the anchorage foundations of the main steel cables, as well as the performance monitoring and analysis of the main steel cables and stabilizing cables, are critical to the overall performance of the suspension bridge. This paper discusses the performance monitoring and analysis of the steel cable deflection and cable strength for this bridge, as well as the main considerations and results of the stability analysis of the bridge abutments and side slopes of the two banks. Water-level observation wells, inclinometers, and tiltmeters monitoring were used to record reference data for the analysis of the slope stability performance. Additionally, the three-dimensional dynamic analysis program VFIFE was used to analyze the deformation and motion of the bridge. The final steady-state results were used to compare the static design value and monitoring data. The dynamic response before the final steady state was also observed.
\end{abstract}

Keywords: monitoring, slope stability, pedestrian suspension bridge, performance, cable deflection, vector form intrinsic finite-element method (VFIFE).

\section{Introduction}

Suspension bridges can be divided into the following five types depending on the installation method: (1) simple suspension bridges, (2) underspanned suspension bridges, (3) stressed ribbon bridges, (4) suspended-deck suspension bridges, and (5) self-anchored suspension bridges. The Baishihu suspension bridge was completed and put into operation in 2010. It has a total length of $116 \mathrm{~m}$, adopting a straight suspension design that is similar to an underspanned suspension bridge. The main structure was connected to the anchor foundations on both sides using three main steel cables. A wooden pedestrian deck was fixed to the main steel cables with steel beams. The bridge body was stabilized using two stabilizing cables, connected to the bridge with 44 steel connecting rods. The components requiring inspection and maintenance are divided into the following items: (1) steel cables, (2) steel connecting rods, (3) anchor foundations, and (4) superstructure. A schematic of the bridge components is shown in Figure 1. Figure 2 shows the on-site configuration of the bridge components and the cross-section of the superstructure.
The setup below the bridge deck is composed of longitudinal, transverse, and main cables. The longitudinal beams have a hollow rectangular steel cross-section, the transverse beams have an I-shaped cross-section, and the main cables consist of three cables with asymmetrical spacings, as shown in Figure 2. Figure 3 shows pictures taken at the anchorage of the main cable (left) and the anchorage

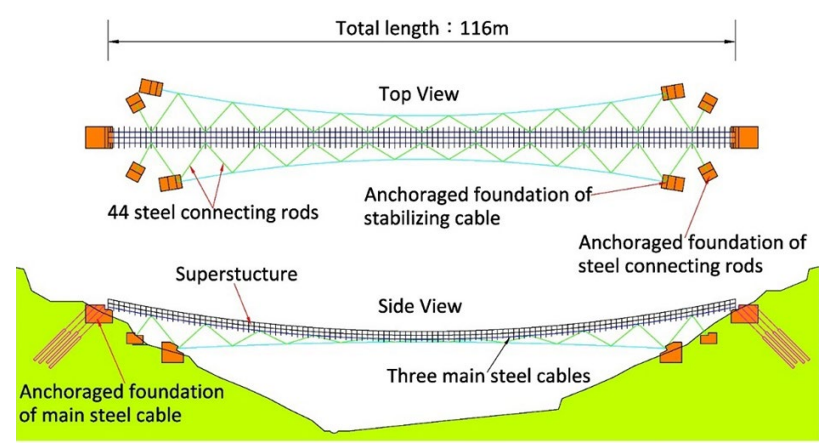

Figure 1. Suspension bridge components

${ }^{*}$ Corresponding author. E-mail: jcjhf@cc.hfu.edu.tw 
of the stabilizing cable (right). To improve the operation and management safety of the suspension bridge, the Geotechnical Engineering Office of Taipei City Government commissioned a professional organization to design an inspection plan for 2011-2018 for the bridge foundation, stabilizing cable foundation, main body of the Baishihu suspension bridge, side slopes at both ends of the abutments, and surrounding groundwater level. According to the inspection plan, regular surveys and observations are carried out (All-wisdom Engineering Consultants, Ltd., 2020) to provide up-to-date information about the overall performance of the suspension bridge structure. In addition, regular safety inspections are performed to check the safety of the suspension bridge.

Recent inspection results have shown that some steel connecting rods and steel structural members exhibit surface corrosion. Two of the steel connecting rods were found to be buckled and rusted during visual inspection in 2019, as shown in Figure 4. These steel rods are considered for replacement by connecting steel cables to avoid buckling, which will be explained later. By applying recent progress in performance monitoring technology and transmission methods, the loss of preforce at the foundation of the abutment is inspected, which evaluates the current performance of the suspension bridge and proposes an overall design plan for the performance maintenance of the suspension bridge. Its main objectives are to monitor the stability of the suspension bridge foundation, ground anchors, steel cables, and side slopes, and to determine the optimum methods for the overall performance maintenance of the suspension bridge, thus ensuring pedestrian safety.

\section{Main component parameters of suspension bridge}

\subsection{Steel cables}

The steel cables comprise three main steel cables and two stabilizing cables. The main steel cables each consist of 19 strands of steel cables with a diameter of $12.7 \mathrm{~mm}$, with an outer layer covered with high-density polyethylene (HDPE). The stabilizing cables each consist of 12 strands of steel cables with a diameter of $12.7 \mathrm{~mm}$, with an outer layer covered with HDPE. The basic parameters of the steel cables are listed in Table 1. The cable type "SWPR7B" is equivalent to "CNS3332", which is the notation of a seven-wire steel strand used in prestressed concrete.
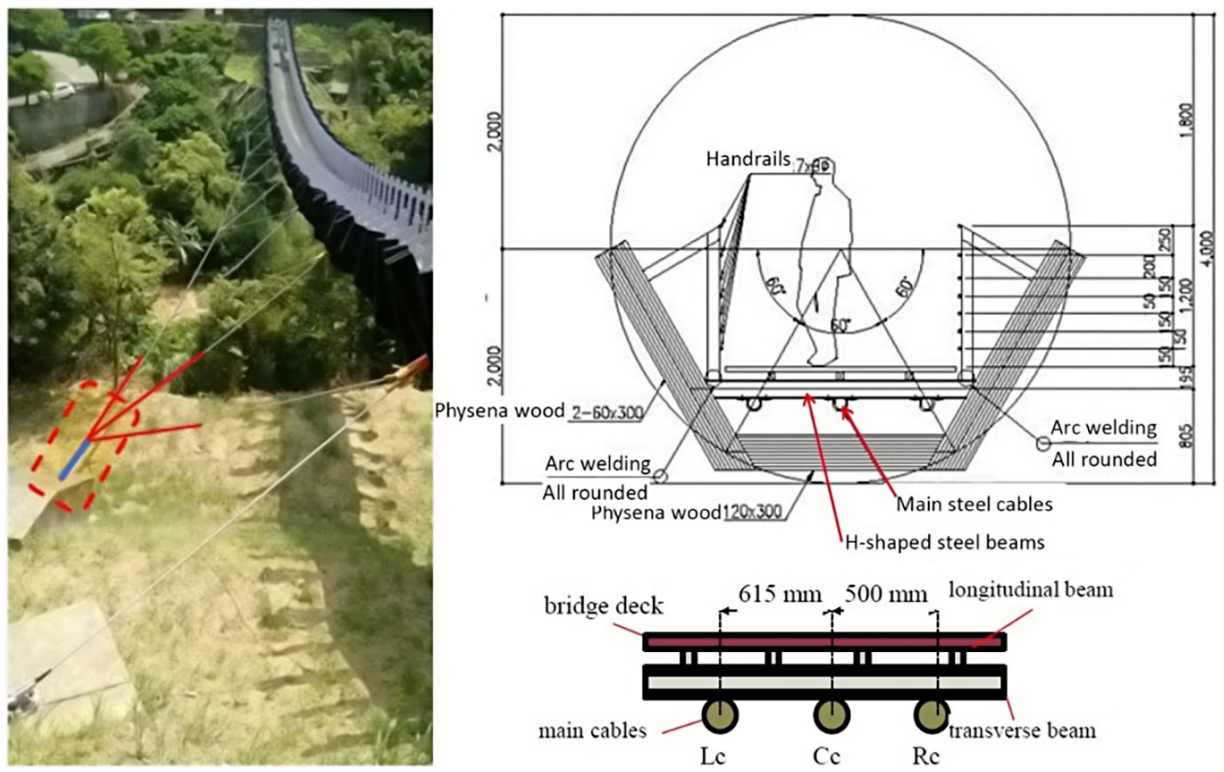

Figure 2. Baishihu Suspension Bridge components and cross-section of superstructure
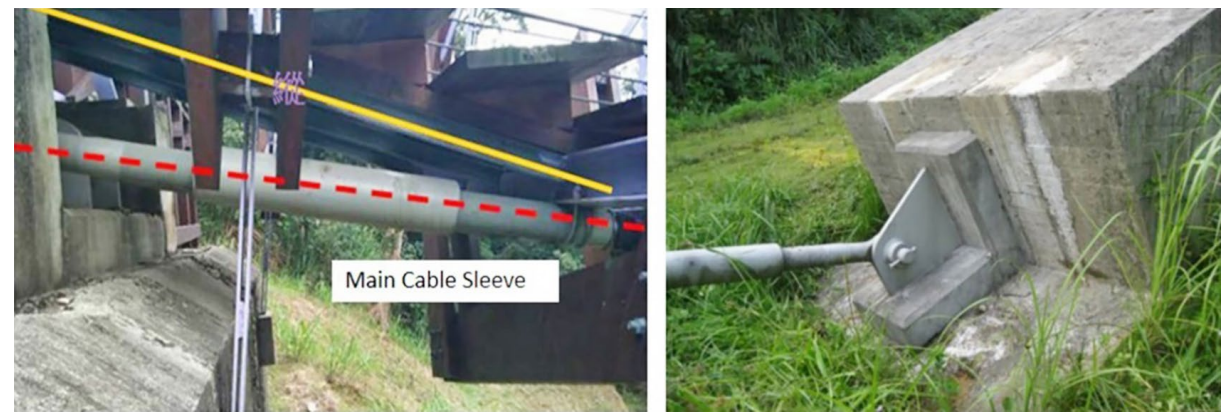

Figure 3. Pictures taken at anchorage of main cable (left) and stabilizing cable (right) 


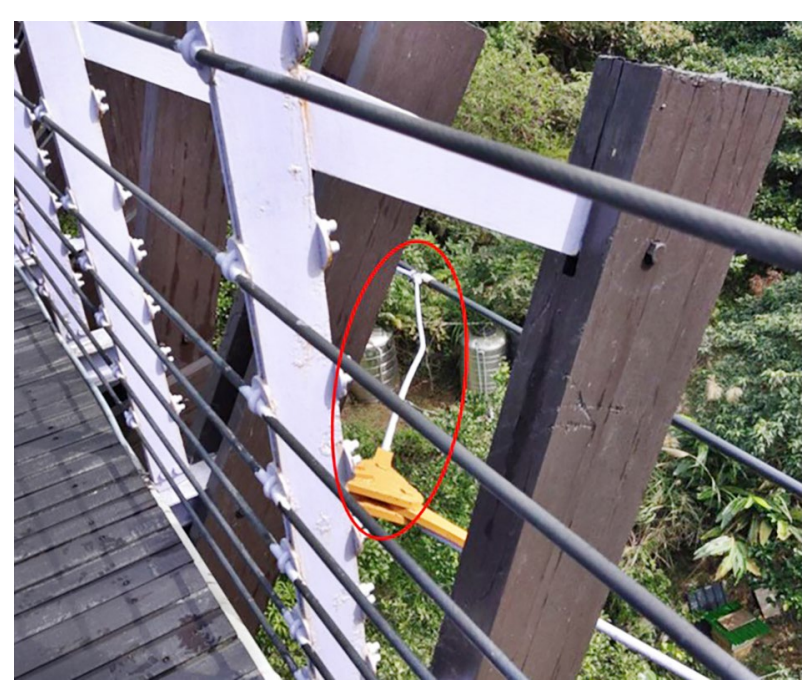

Figure 4. One of the buckled and rusted steel connecting rods

The strand outside diameter is $12.7 \mathrm{~mm}$, the minimum yielding force $P_{y}$ is $155.82 \mathrm{kN}$, and the minimum break tension $P_{u}$ is $183.26 \mathrm{kN}$. The "SBPR95/120" notation is equivalent to "CNS9272", which implies the circular steel rod used in prestressed concrete. The minimum yielding strength $F_{p y}$ is $931000 \mathrm{kN} / \mathrm{m}^{2}\left(=95 \mathrm{~kg} / \mathrm{mm}^{2}\right)$, and the minimum tension strength $F_{p u}$ is $1176000 \mathrm{kN} / \mathrm{m}^{2}\left(=120 \mathrm{~kg} / \mathrm{mm}^{2}\right)$.

The ultimate tensile force $P_{u}$ of the main steel cables of the suspension bridge is $3485.5 \mathrm{kN}$, and yield force $F_{y}$ is $2962.6 \mathrm{kN}$. Based on limit state design (LSD), the maximum tensile force $\left(P_{d}\right)$ of a single cable under various conditions is calculated to be $1386.2 \mathrm{kN}$, whereas the strength reduction factor $(\Phi)$ is taken as 0.9 . Thus, the design safety factor for the maximum cable tension $\mathrm{SF}=\Phi F_{y} / P_{d}=1.92$, is larger than 1 , indicating that safety is guaranteed.

\subsection{Steel connecting rods}

The 44 steel connecting rods of the Baishihu suspension bridge were made of $32 \mathrm{~mm}$ diameter solid steel, which were welded and bolted at the ends to form a connection between the main steel cables and the stabilization cables. The basic parameters of the steel rods are listed in Table 1.

For the steel connecting rods, the yield stress $f_{y}$ is $235359.6 \mathrm{kN} / \mathrm{m}^{2}$ and the allowable stress $f_{t}$ is $211823.6 \mathrm{kN} / \mathrm{m}^{2}$. Based on LSD, the maximum tensile force $\left(P_{d}\right)$ of a single steel rod under various conditions was calculated to be $151.07 \mathrm{kN}$, and the cross-sectional area of the steel $\operatorname{rod} A$ is $8.04 \mathrm{~cm}^{2}$; thus, $\mathrm{SF}=A f_{t} / P_{d}=$ $(8.04 \times 211823.6) / 151.07 \times 10000=1.12$, is larger than 1 , indicating that safety is guaranteed.

\subsection{Anchor foundation}

The anchor foundations consisted of: (1) two anchor foundations for the main steel cables, which were each connected to 16 ground anchors with a prestressing force of $784.8 \mathrm{kN}$ and to the main steel cables using hydraulic compression fittings; and (2) four anchor foundations for the stabilizing cables, which were each connected to four ground anchors with a prestressing force of $784.8 \mathrm{kN}$ and to the stabilizing cables using hydraulic compression fittings. The results are shown in Figure 5. Figures $5 \mathrm{a}$ and $5 \mathrm{~b}$ show cross sections of the anchor foundations of the main steel cable and the stabilizing cable.

Table 1. Basic information of steel cables and steel connecting rods

\begin{tabular}{|l|l|c|c|c|c|}
\hline \multirow{2}{*}{ Components } & \multirow{2}{*}{ Type } & Diameter & Elongation & Break tension & Effective tension \\
\cline { 3 - 6 } & & $\mathrm{mm}$ & $\%$ & $\mathrm{kN}$ & $\mathrm{kN}$ \\
\hline Steel cables & SWPR7B & 12.7 & 3 & 266.8 & 105.9 \\
\hline Steel connecting rods & SBPR95/120 & 32 & 5 & 144.2 \\
\hline
\end{tabular}

a)

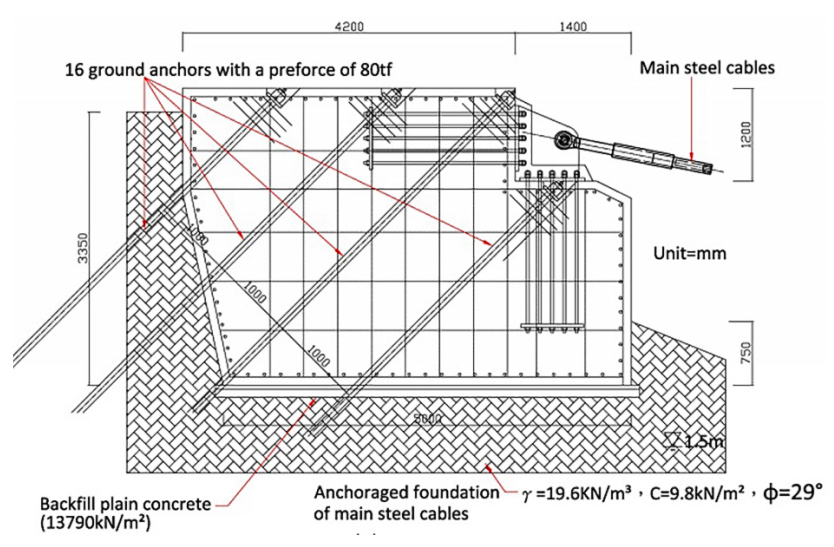

b)

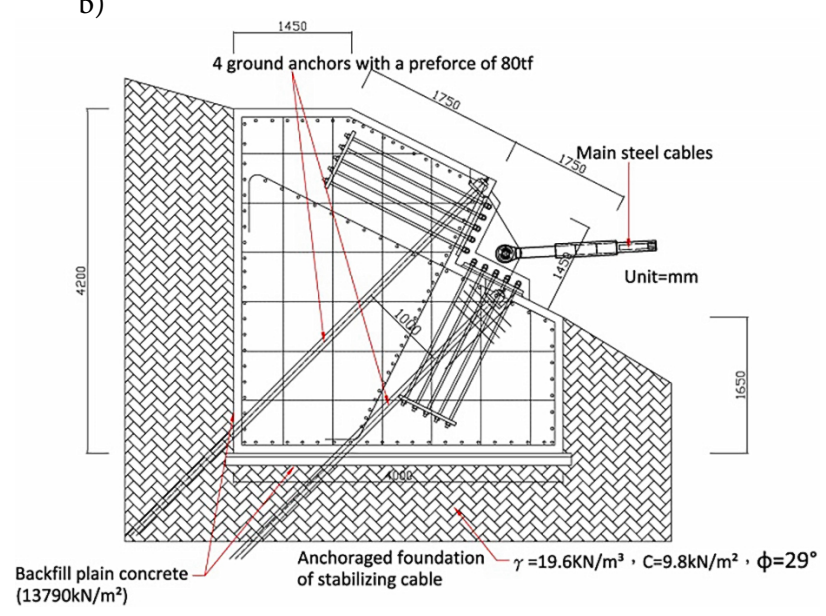

Figure 5. Cross-sections of the anchor foundations of: $\mathrm{a}$ - main steel cable; $\mathrm{b}$ - stabilizing cable 


\subsection{Superstructure}

The superstructure consisted of: (1) handrails made of steel plates and steel cables with a diameter of $9 \mathrm{~mm}$, with an outer layer of steel cables covered with PE, and $\mathrm{H}$-shaped steel beams; (2) a wooden bridge deck made of southern pine; and (3) a keel for the bridge body made of Physena wood, as shown in Figure 2.

\section{Overall performance evaluation and analysis method of suspension bridge}

\subsection{Comprehensive analysis method of suspension bridge monitoring data over time}

\subsubsection{Performance monitoring of suspension bridge central deflection}

The central deflection of the suspension bridge caused by both the life load and dead load, including the weight of the cable, is measured monthly. A high-accuracy Leica Sprinter 250M electronic level device was used to measure the vertical deflection of the central point of the suspension bridge with respect to the zero line connected between the southern and the northern bridge abutments (shown in Figure 6). The vertical datum points were set in the northern and southern flat grounds, away from the abutments. The error in the round-trip measurement per kilometer was below $0.7 \mathrm{~mm}$. Considering the possible influence of the life load of tourists, most measurement times were arranged in the early morning at 8 A.M. to minimize the effect of tourists. Because the direct relationship between the cable tension and central deflection

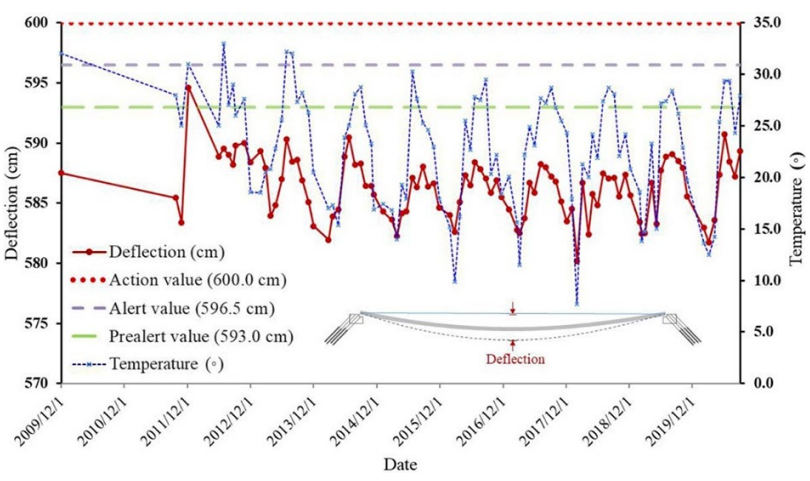

Figure 6. Results of temperature monitoring and changes in the central deflection of the suspension bridge of the suspension bridge is known, a comparison of the long-term monitoring results of the central deflection and its alert level value can be used as a reference for subsequent performance management, as shown in Table 2. It is known that the actual deflection of the Baishihu suspension bridge was $587.5 \mathrm{~cm}$ when it was completed in early 2010, and the initial design deflection was $600.0 \mathrm{~cm}$. This difference of $12.5 \mathrm{~cm}$ is the tolerance; hence, approximately $50 \%$ of this tolerance is taken to calculate the prealert level as $592 \mathrm{~cm}$, while the action level is set at the design deflection of $600 \mathrm{~cm}$. The alert value is the average of the two values above. The results of monitoring the temperature and central deflection of the Baishihu suspension bridge are shown in Figure 6. It can be seen that the change in deflection has a direct positive correlation with temperature, and all the deflection values are under the alert value, which indicates that the main cables of the suspension bridge remained in a safe condition.

\subsubsection{Suspension bridge side slope performance monitoring}

Side slope performance monitoring records the variation of various data, such as (1) water-level in an observation well, (2) inclinometer in the soil, and (3) suspension bridge foundation tiltmeter monitoring. Changes in these data can reveal the behaviors and patterns of slope sliding failures, the details of which are shown in Figures 7-9. Figure 10 shows the location of the monitoring system for the suspension bridge and the side slope. There were six tiltmeters set in the foundations of the main steel cables and stabilizing cables; No. Tl1- $\mathrm{Tl} 3$ were set in the northern side foundations, and No. Tl4-Tl6 were set in the southern side foundations. Three of the four groundwater observation wells were located on the northern slope, and one placed on the southern slope. No. OW1 was destroyed two years ago; therefore, new No. OW4 was built, and only three observational data were adopted in this study. Two inclinometer tubes, No. SO1 and $\mathrm{SO}$, were drilled into two side slopes with a $21 \mathrm{~m}$ depth. The deflection measuring points and datum points for the central vertical deflection of the suspension bridge are also shown in Figure 10. Figure 7 shows that the groundwater variation of the side slope is correlated with the monthly rainfall. During some periods of time the groundwater level rose up to the alert value.

Table 2. Central deflection management values and treatment principles at each level

\begin{tabular}{|l|l|l|}
\hline \multicolumn{1}{|c|}{ Item } & \multicolumn{1}{|c|}{ General meaning } & \multicolumn{1}{c|}{ Treatment principles to be adopted } \\
\hline $\begin{array}{l}\text { Prealert value } \\
(592 \mathrm{~cm})\end{array}$ & $\begin{array}{l}\text { 1. Within design scope } \\
\text { 2. Acceptable change } \\
\text { 3. Should be within safe range }\end{array}$ & $\begin{array}{l}\text { 1. Further observation } \\
\text { 2. Pay attention to subsequent changes }\end{array}$ \\
\hline $\begin{array}{l}\text { Alert value } \\
(596 \mathrm{~cm})\end{array}$ & $\begin{array}{l}\text { 1. Greater than design value but within allowable range } \\
\text { 2. Close to the critical action value }\end{array}$ & $\begin{array}{l}\text { 1. Normal use with close observation } \\
\text { 2. Study safety concerns and develop countermeasures }\end{array}$ \\
\hline $\begin{array}{l}\text { Action value } \\
(600 \mathrm{~cm})\end{array}$ & $\begin{array}{l}\text { 1. Greater than design value and close to nonallowable } \\
\text { range }\end{array}$ & $\begin{array}{l}\text { 1. Suspend use with close observation } \\
\text { 2. Implement countermeasures before action value } \\
\text { is reached }\end{array}$ \\
\hline
\end{tabular}




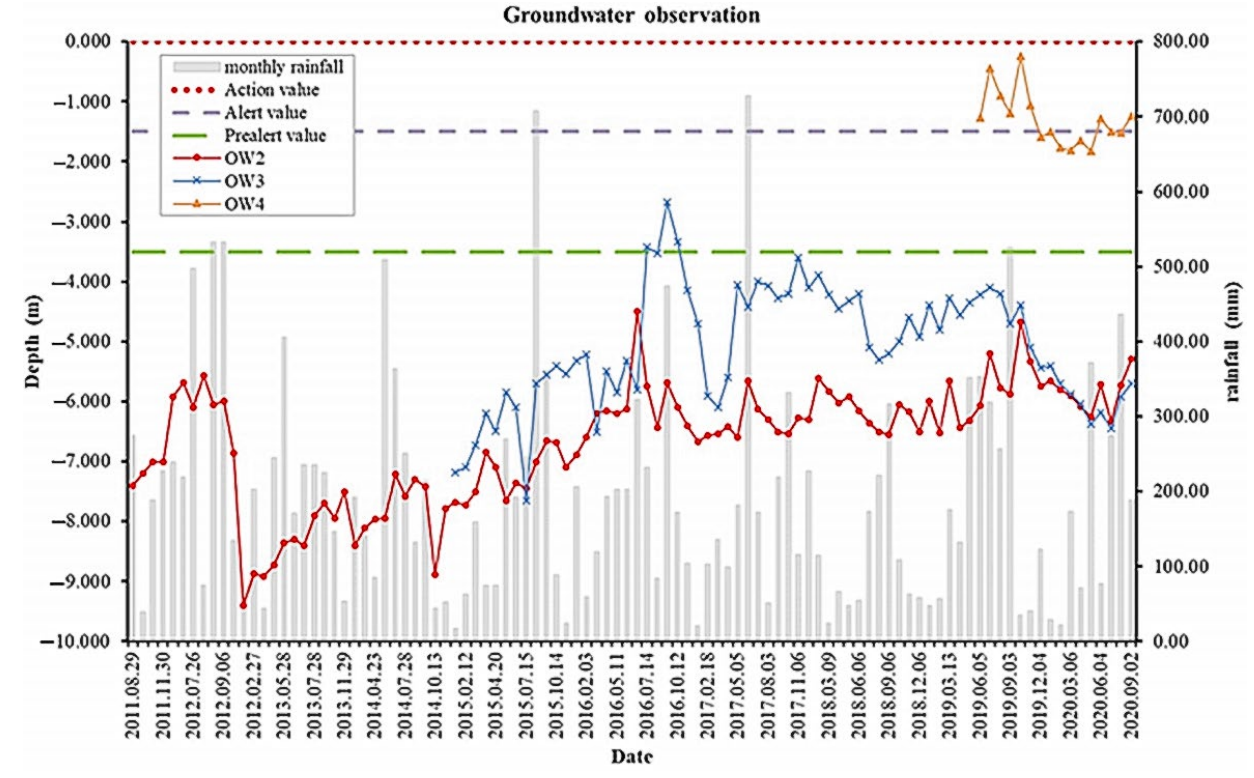

Figure 7. Monitoring results of water level changes in the side slope well with time

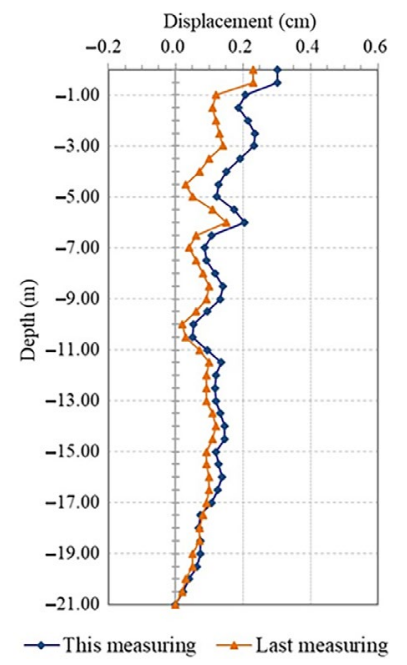

Figure 8. Monitoring results of changes in the inclinometer at the side slope of the suspension bridge with depth

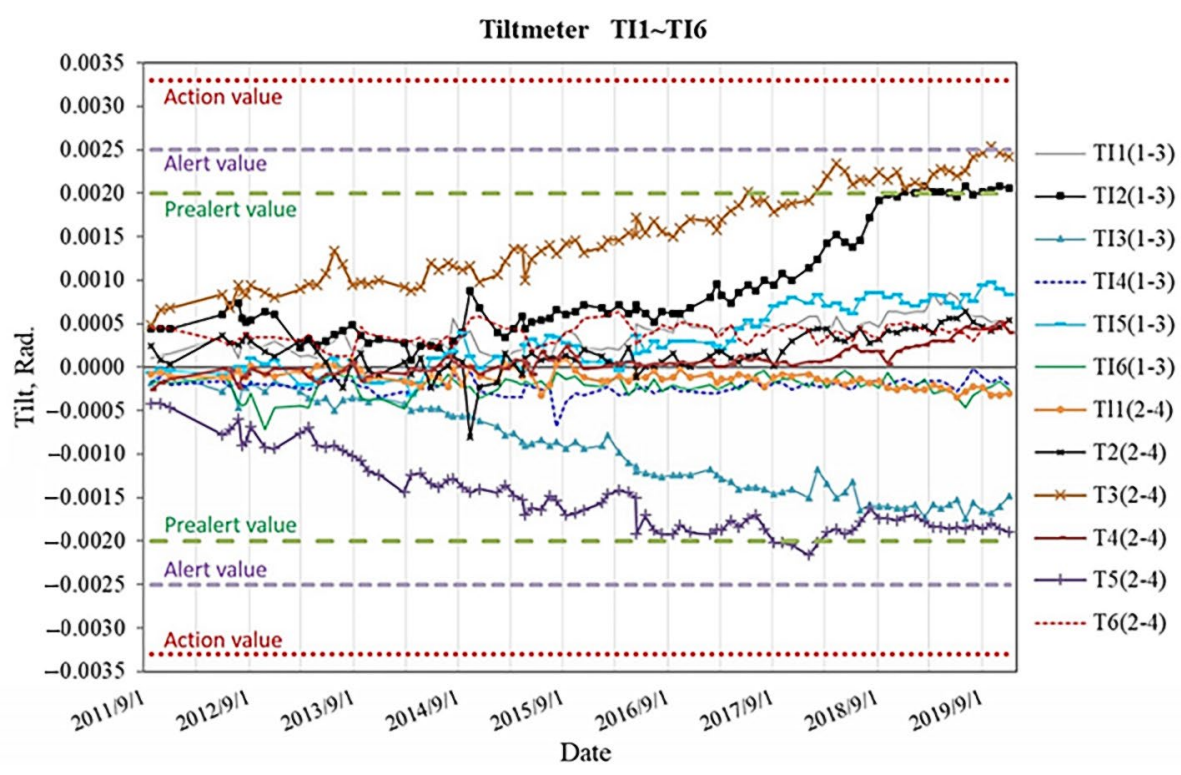

Figure 9. Monitoring results of changes in tiltmeter at the side slope of the suspension bridge with time

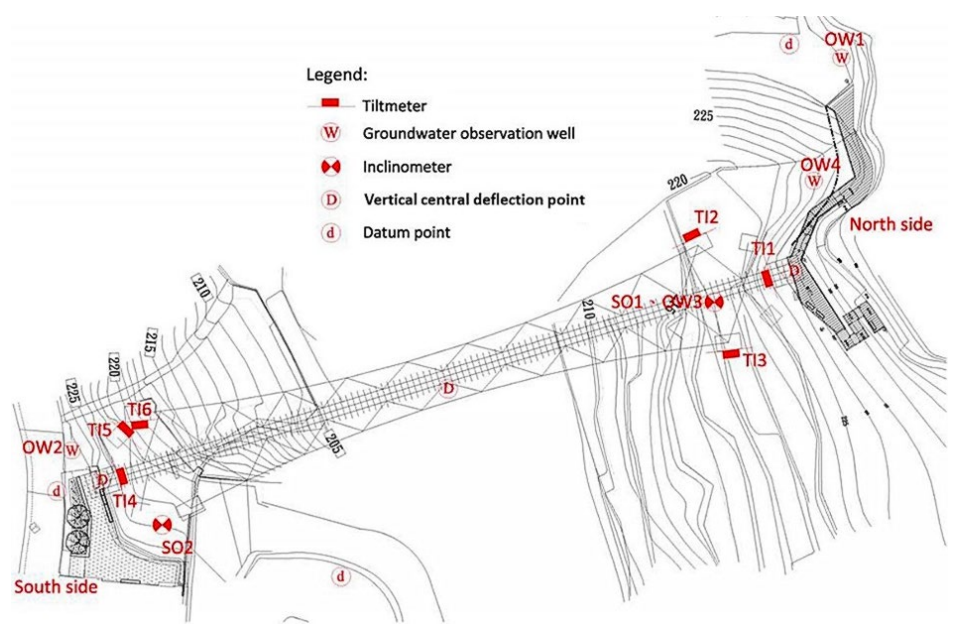

Figure 10. Location of monitoring system for suspension bridge and side slope 
However, according to the inclinometer measurements shown in Figure 8, the displacement value is negligible, which means the side slope remained stable and no sliding failure surface was generated along the depth of the slope. Figure 9 indicates that although the tiltmeter value for the southern foundation of the stabilizing cable reached the prealert limit, most of the tiltmeter data are under the alert value, which shows that the anchorage foundations of both the main cables and the stabilizing cables were in a stable situation. These figures show that most monitoring results remained in a stable condition over time and were under the alert values.

\subsection{Performance analysis method of main cables}

In this study, a 3D rigid frame element dynamic analysis program was used (Brownjohn et al., 1994), which was based on the vector form intrinsic finite-element method (VFIFE). It was the primary tool for the performance analysis of the main cables, and was also used for conducting bridge deformation and motion analyses. The basic theory was proposed by Ting et al. (2004a, 2004b, 2012) from Purdue University. It is different from conventional finite element analysis (FEA) in that it analyzes continuum body displacements based on partial differential equations. VFIFE describes the displacement of any mass point in the structure using the vector motion equation of that point based on a physical model describing discrete rigid body motion. Because it is not necessary to solve the analytical equations using matrix calculation and iterative methods, it is suitable for solving problems involving geometric nonlinearity due to small deformations and large displacements of the structure, such as the large displacement of rigid body suspension cable structures caused by external forces. In addition, because the fundamental theory is not limited to a continuum body, it is also applicable for predicting the subsequent behavior of the bridge owing to material damage. This analysis model has been previously applied to the dynamic analysis of the influence of earthquakes and wind on the Bitan Bridge in northern Taiwan, stability analysis of the slipped tower foundation of Taiwan Power, and other research studies involving the moving load, element fracture, system structural buckling, suspension cable vibrations, and energy dissipation of reinforced structures. Shih et al. (2012) used the VFIFE method to simulate a vehicle, track, and bridge and showed that it could provide an effective numerical method for the vehicle-track-bridge interaction behaviors. Duan et al. (2014) presented a formulation for the integration of the VFIFE method and fiber beam-column element model, and successfully simulated the entire process of structural damage and collapse for cable-stayed bridges. After nearly 20 years of development, VFIFE is now a fairly mature theoretical and practical analysis tool (Wang, 2005; Sen, 2018; Chen, 2011; Lee, 2015).

The VFIFE dynamic analysis program was applied in this study to analyze the stability performance of the Baishihu suspension bridge. The main objectives of the performance included analysis of the internal force, vertical deflection, and lateral displacement of the steel cables in the bridge. The final steady-state results obtained from the program output were used to compare the static design value and monitoring data, and the dynamic response with different damping coefficient before the final steady state was also observed. The Rayleigh damping coefficient was adopted for the bridge structure, and the particle motion equations are described as follows:

$$
\begin{aligned}
& {[\mathrm{C}]=a_{0}[\mathrm{~K}]+a_{1}[\mathrm{M}]} \\
& m_{i} a_{i}(t)+c_{i} v_{i}(t)+\operatorname{fint}_{i}(t)=\operatorname{fext}_{i}(t), i=1-n .
\end{aligned}
$$

In Eqn (1), $\mathrm{C}$ denotes the damping matrix, $\mathrm{K}$ the stiffness matrix, and $M$ the mass matrix. Since the VFIFE does not need to construct a $\mathrm{K}$ matrix, and $\mathrm{M}$ is a diagonal matrix such that $a_{0}=0$ and $\mathrm{a}_{1}=c$, the overall system damping [C] is discrete to $C_{i i}=c M_{i i}$ and $C_{i j}=0$. This damping is then transformed into the particle motion Eqn (2), where fint $_{i}$ denotes the internal force function of time, fext $t_{i}$ the external force function of time, and $n$ the nodal number. All the numerical analysis results are presented and discussed in Section 3.3.

\section{Overall performance analysis results of the suspension bridge}

\subsection{Analysis of suspension bridge central deflection}

The measured deflection in December 2019 was $585.67 \mathrm{~cm}$. Compared with the deflection at completion $(587.50 \mathrm{~cm})$, there was a change of $1.83 \mathrm{~cm}$. Historical monitoring data showed that the deflection was within the range $580-591 \mathrm{~cm}$. Superimposing the historical monitoring data, as shown by the red color points in Figure 6, and on-site temperature observation data, as shown by the blue color points in Figure 6, shows that changes in the two datasets varied in a similar trend, and because on-site measurements were taken at $8 \mathrm{am}$, the impact due to the load by tourists could be eliminated. Therefore, the measured changes in the deflection of the suspension bridge are primarily due to the temperature effect, as shown in Figure 6. After careful study, it was concluded that there were no abnormal conditions, such as loosening or permanent tensile deformation of the main steel cables of the suspension bridge, and the changes in central deflection were less than the prealert threshold value, except for one measurement data point in December 2011 that could be an error, as regular measurements were not yet in place.

\subsection{Stability analysis of side slope performance}

The slope performance analysis of this site mainly examines the side slopes on both sides of the suspension bridge abutment. According to the topography and drilling test data, the soil layer can be divided into soil cover and rock, in addition to the RC foundation structure. The parameters of the soil layer simplified from the drilling test results are summarized in Table 3. Moreover, the tensile load of 
Table 3. Parameters of side slope stability analysis

\begin{tabular}{|l|c|c|c|c|}
\hline \multirow{2}{*}{ Soil layer Parameter } & $\mathrm{C}$ & $\psi$ & $\gamma_{t}$ & $\gamma_{\text {sat }}$ \\
\cline { 2 - 5 } & $\mathrm{kN} / \mathrm{m}^{2}$ & (degree) & $\mathrm{kN} / \mathrm{m}^{3}$ & $\mathrm{kN} / \mathrm{m}^{3}$ \\
\hline Soil cover & 10 & 29 & 20 & 20 \\
\hline Rock & 70 & 33 & 26 & 26 \\
\hline
\end{tabular}

the suspension bridge steel cables was considered in the analysis. The computer program used in the analysis was STABL5, which was developed by Carpenter (1986) from Purdue University.

The slopes on the north and south sides of the bridge abutment were analyzed, including several conditions, such as under normal conditions, with earthquakes, heavy rain, both heavy rain and earthquakes, and with constant plane sliding. The recommended safety factor $(\mathrm{SF})_{\mathrm{r}}$ was $1.5,1.1,1.2,1.05$, and 1.5. The north side is a dip slope; therefore, a plane sliding analysis model was used, while the arc sliding analysis model was adopted for the remaining slopes. A comparison between the analysis results and the general recommended values for $(\mathrm{SF})_{\mathrm{r}}$ is shown in Table 4 . The northern slope provides a safety factor that meets the requirements under all conditions considered, and therefore, the side slope is considered stable.

The southern slope has been reinforced in the past, as shown in Figure 11. According to the results of a subsequent in situ ground anchor lift-off test, as shown in the three test curves in Figure 12, the original design preforce was $294.3 \mathrm{kN}$. In the 3 anchor life-off tests, the lift preforce

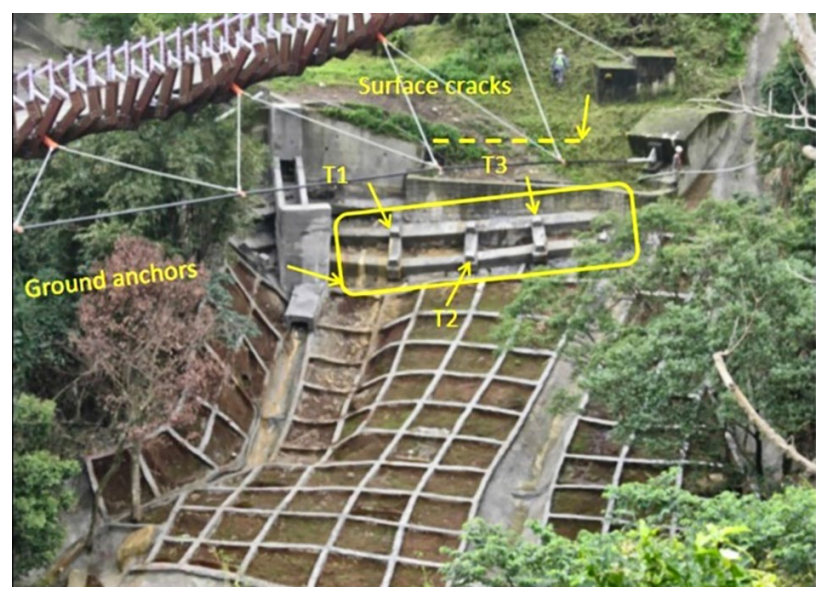

Figure 11. Photo of southern slope after reinforcement was $112.8 \mathrm{kN}, 171.7 \mathrm{kN}$ and $176.8 \mathrm{kN}$, respectively, and the total residual preforce was $52.24 \%$. In addition, cracks were discovered near the free end of the anchor head, which were filled after inspection, and the rust on the steel tendons was relatively mild. The measured values of the preforce were again input to analyze the side slope section. Under normal conditions and with both heavy rain and earthquakes, the safety factor is smaller than the generally recommended values. Figure 12 shows the analysis results of the southern slope with both heavy rain and earthquake conditions. The comprehensive evaluation results indicate that the southern slope requires further reinforcement.

\subsection{Analysis of main cable performance}

\subsubsection{Analysis of cable internal force with dead weight load}

The design load conditions of the suspension bridge were according to the Highway Bridge Design Code issued by the Ministry of Transportation and Communications, Republic of China (2009). As shown in Figures 1 and 2, the mechanical model of the bridge structure was established based on the design diagram geometry and site configuration. The parameters of the structural cross-sections are listed in Table 5. A 3D analysis model of the bridge is shown in Figure 13. Finally, the model was used to solve for the internal force of the main cables in the axial direction under a dead load. The calculated internal forces were compared to the original structural design values for calibration. A comparison between the calculated internal force and the design internal forces is shown in Figure 14. The design forces are shown in black, which are $380.72 \mathrm{kN}$ in the north side (right-hand side in Figure 14) and $380.92 \mathrm{kN}$ in the south side (left-hand side in Figure 14), and the calculated forces of the three main cables are shown in blue, red, and green, respectively. The values of calculated forces in the north side were between $373.04 \mathrm{kN}$ and $400.45 \mathrm{kN}$, with an average of $388.39 \mathrm{kN}$, and those in the south side were between 373.04 and $400.47 \mathrm{kN}$, with an average of $388.40 \mathrm{kN}$. Because the actual spans between the three main cables are slightly different, as shown in Figure 2, the span between the left cable (Lc) and the central cable $(\mathrm{Cc})$ is $615 \mathrm{~mm}$, which is larger than the span between the right cable $(\mathrm{Rc})$ and $\mathrm{Cc}(500 \mathrm{~mm})$. Thus, there is a slight difference (approximately 6\%) between the calculated internal forces of the three main cables.

Table 4. Safety factor results of slope stability analysis

\begin{tabular}{|l|c|c|c|}
\hline \multirow{2}{*}{ Condition } & North & \multicolumn{2}{c|}{ South } \\
\cline { 2 - 4 } & Design anchor preforce & Design anchor preforce & In situ measured preforce \\
\hline Normal, $(\mathrm{SF})_{\mathrm{r}}=1.5$ & 1.82 & 1.66 & 1.47 \\
\hline Earthquake, $(\mathrm{SF})_{\mathrm{r}}=1.1$ & 1.38 & 1.21 & 1.17 \\
\hline Heavy rain, $(\mathrm{SF})_{\mathrm{r}}=1.2$ & 1.74 & 1.28 & 1.22 \\
\hline Heavy rain and earthquake, $(\mathrm{SF})_{\mathrm{r}}=1.05$ & 1.31 & 1.18 & 0.97 \\
\hline Constant plane sliding, $(\mathrm{SF})_{\mathrm{r}}=1.5$ & 1.54 & $\mathrm{NA}$ & NA \\
\hline
\end{tabular}




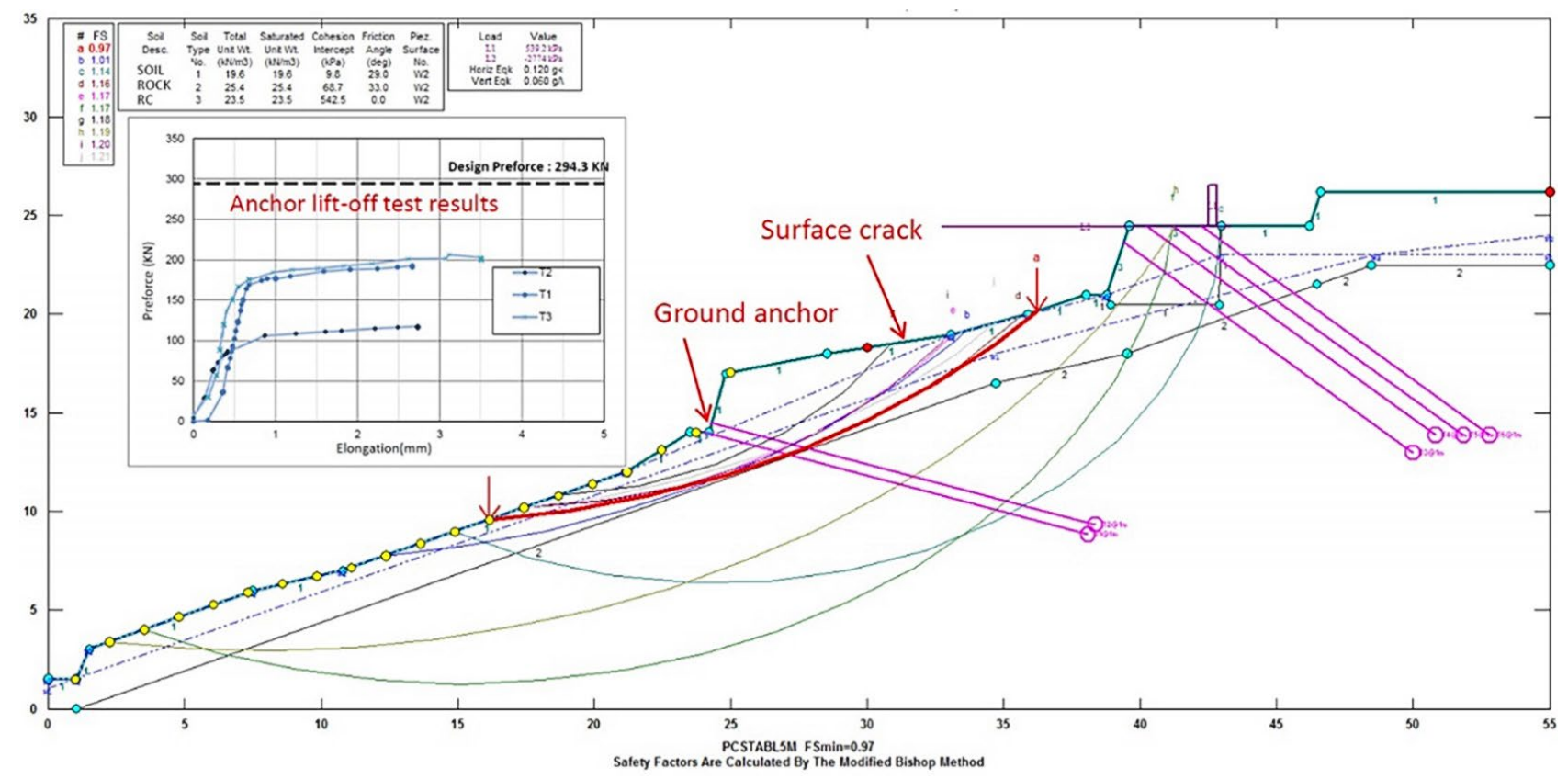

Figure 12. Analysis result of southern slope with both heavy rain and earthquake condition

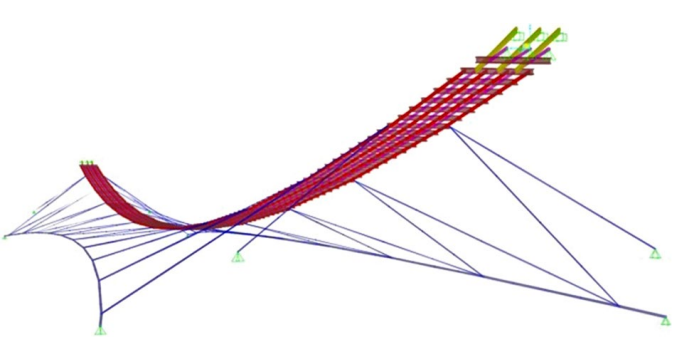

Figure 13. Finite-element model of Baishihu Suspension Bridge

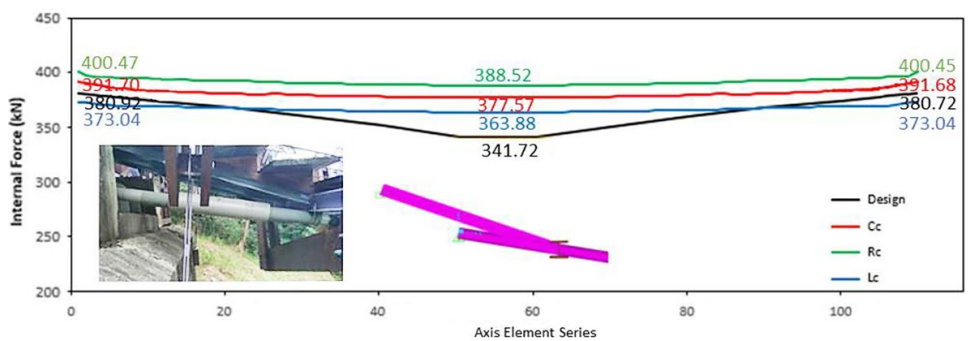

Figure 14. Analysis results of cable forces under dead weight of Baishihu Bridge

Table 5. Parameters of structural cross-sections

\begin{tabular}{|l|l|l|l|l|}
\hline \multicolumn{1}{|c|}{ Component } & \multicolumn{1}{c|}{ Cross-section } & \multicolumn{1}{c|}{ Shape } & \multicolumn{1}{c|}{ Material } & \multicolumn{1}{c|}{ Dimension (mm) } \\
\hline Transverse beam & HB150 & I-shaped & Steel G50 & $150 \times 150 \times 7 \times 10$ \\
\hline Longitudinal beam & HSS & Hollow rectangle & Steel G50 & $75 \times 50 \times 4$ \\
\hline Main cable & PC1 & Solid round & Tendon & D45 \\
\hline Stabilizing cable & PC2 & Solid round & Tendon & D44 \\
\hline Connecting rod & TR1 & Solid round & Steel rod & D32 \\
\hline Longitudinal beam at bridge ends & HSnWF & Symmetrical cross-section & Steel G50 & Composite cross-section \\
\hline
\end{tabular}

Note: Steel G50, Tendon, Steel rod: $\mathrm{E}=-1.95 \mathrm{E}+11 \mathrm{~N} / \mathrm{m}^{2}, \rho=7849 \mathrm{~kg} / \mathrm{m}^{3}$.

The maximum internal forces occurred in the abutments of the two sides. The aforementioned design forces, $380.72-380.92 \mathrm{kN}$, generally lay within the average variation in the calculated forces between the two sides, that is, the average of $388.39 \mathrm{kN}$ and $388.40 \mathrm{kN}$. The error percentage was approximately $2 \%$. This $3 \mathrm{D}$ model was used to analyze and discuss the forces and deflections of the suspension bridge.

\subsubsection{Analysis of main cable deflection due to temperature and validation of the simulation model}

Past temperature and monitoring data of the deflection of the Baishihu suspension bridge, as shown in Figure 6, were used to calculate the temperature difference for each subsequent observation after December 1, 2009. On this date, the first temperature measurement at $32^{\circ} \mathrm{C}$ was taken as the standard temperature of the bridge in its completed state. The distribution of the central deflection relative to temperature can be found through regression analysis, which reveals that the relationship between temperature 
and deflection can be represented as $d(t)=0.2927 t+$ 578.89, as shown by the blue dotted line in Figure 15. Values of $\Delta t_{1}=-10{ }^{\circ} \mathrm{C}$ (i.e., $22{ }^{\circ} \mathrm{C}$ ) and $\Delta t_{2}=-20{ }^{\circ} \mathrm{C}$ (i.e., $12^{\circ} \mathrm{C}$ ) were used in the subsequent analysis to observe the relationship between temperature and deflection.

The analysis of temperature difference uses the following theoretical formula to consider the effective axial force due to temperature when calculating the longitudinal forces of the three main cables in the model:

$$
\Delta f_{\mathrm{T}}=\alpha \cdot \Delta t \cdot E A,
$$

where $\alpha$ is the coefficient of thermal expansion, $\Delta t$ is the temperature difference, and $E A$ is the stiffness of the main cables. However, because the main cables are made of steel coated with HDPE, the thermal coefficient of steel $\alpha_{s}$ is initially $1.170 \times 10^{-5} /{ }^{\circ} \mathrm{C}$, and the analysis results are shown in Table 6.

Table 6. Analysis results of deflection with different temperatures

\begin{tabular}{|c|c|c|c|}
\hline No. & $\begin{array}{c}\text { Temperature } \\
\left({ }^{\circ} \mathrm{C}\right)\end{array}$ & $\begin{array}{c}\text { Temperature } \\
\text { difference }\left({ }^{\circ} \mathrm{C}\right)\end{array}$ & Deflection $(\mathrm{cm})$ \\
\hline 1 & 32 & 0 & 587.64 \\
\hline 2 & 22 & -10 & 582.22 \\
\hline 3 & 12 & -20 & 577.13 \\
\hline
\end{tabular}

The deflection analysis results for the steel cable for the three different temperatures are shown by the green line in Figure 15. It was found that the deflection was smaller than the experimental results, indicating that the current coefficient of thermal expansion for the steel is conservative. Considering that the heating of the cables in reality is affected by the outer HDPE wrapping material, the temperature of the steel cables under heating is different from that of the ambient environment. Therefore, the change in deflection must be adjusted using the test results of the compound coefficient of thermal expansion with a combination of steel and HDPE. This leads to $\alpha_{t}=7.630 \times 10^{-6} /{ }^{\circ} \mathrm{C}$ as the final compound thermal coefficient, which gives a relationship that is the closest to the relationship between the measured temperature and deflection, as shown by the red line in Figure 15. The trend after the adjustment agrees well with the regression line of the experimental results, indicating that it can be used for subsequent predictions.

The 3D VFIFE numerical model, mentioned in Section 2.2, validated the calculated internal forces of the bridge main cables with the original design value, as described in Section 3.3.1, and modified the compound coefficient of thermal expansion. Furthermore, this model was used to validate the bridge's central deflection simulation using the monitoring data. Figure 16 depicts the comparison between the simulation results and observation. Considering that in the early years, the regular measurements were not yet in place, as mentioned in Section 3.1, and only the results obtained after 2015 were adopted for com-

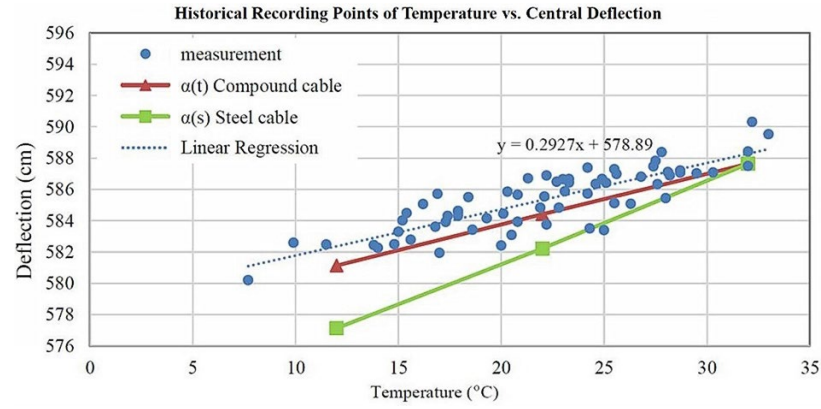

Figure 15. Regression curve of Baishihu suspension bridge main cable deflection with temperature

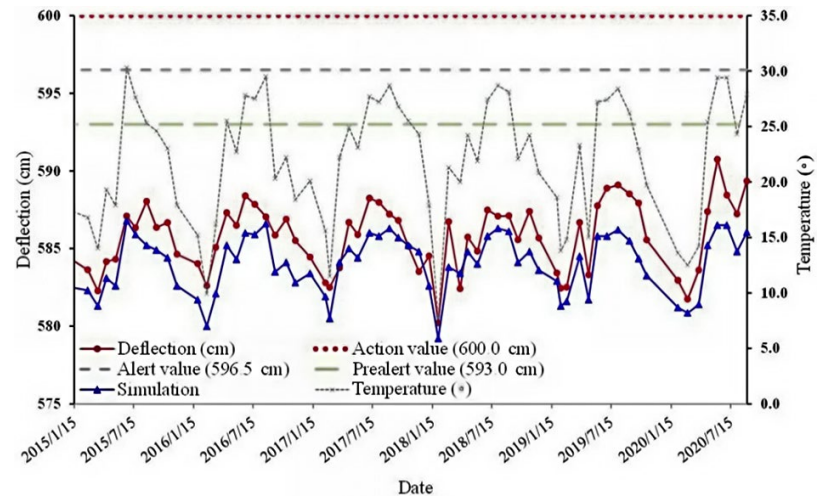

Figure 16. Comparison between the simulation results and observation of main cable central deflection

parison. The trend of the simulation curve was similar to that of the observation results. The quantitative difference between them was approximately $1.58 \mathrm{~cm}$ on average with a maximum of approximately $2.29 \mathrm{~cm}$. This was equivalent to an error percentage of approximately $0.27-0.39 \%$ for an average deflection of $585 \mathrm{~cm}$. The difference could be attributed to the possible influence of the live tourist load and the wind force applied during the observation.

\subsubsection{Performance analysis of steel connecting rods after replacement}

As shown in Figure 4, the results of the on-site visual inspection revealed that the two steel connecting rods were buckled and damaged. It is understood that the original design used steel rods to reduce the shaking of the suspension bridge. However, to avoid buckling after replacing the steel connecting rods again, replacing all the steel connecting rods on site with steel cables having equal crosssectional areas was considered. In terms of physical characteristics, steel connecting rods have a higher bending stiffness than steel cables with equal cross-sectional areas. However, owing to the slenderness ratio of a steel rod, under the influence of bending owing to its own weight, and because of the movement of the suspension bridge due to transverse winds, the resultant force on the steel rod does not pass through the center of its cross-section under the action of axial compression. Therefore, the axial force leads to a secondary bending effect on the steel rod crosssection, causing buckling. As a result, part of the material 
in the cross-section undergoes plastic deformation such that the steel rod cannot return to its original straightness. However, although the steel cable is also subject to a secondary bending moment caused by its own weight and axial compression, its bending stiffness is almost negligible compared to that of the steel rod. As such, the steel cable can bend arbitrarily without generating an internal bending moment, exhibiting no resistance to axial compression. The following simulation is used to explore the possibility of replacing the steel connecting rods with cables and to determine the difference in the performance of the cable under transverse wind after replacement.

In the simulation model, an external force $P$ that represents the resultant force on the suspension bridge due to wind is applied in the lateral direction to the central node of the bridge deck, as shown in Figure 17. There were 44 steel connecting rods in the lateral direction, which were replaced by 44 steel cables at the same respective locations. Displacements in the two scenarios were compared, and the results are shown in Figure 18. The central node of the bridge with steel connecting rods moved by $0.0012 \mathrm{~m}$, whereas with steel cables, it moved $0.0019 \mathrm{~m}$ in the lateral direction. The cable displacement was 1.58 times that of the steel connecting rods, for the reasons described above. As the steel cables are unable to withstand the load, they fail to provide complete lateral restraint under the pressure of the suspension bridge.

To understand the behavior of the entire suspension bridge under different lateral uniform forces $\mathrm{W}$ with the two configurations, the lateral uniform forces $W=0.102$, $0.204,0.306,0.409$, and $1.022 \mathrm{kN} / \mathrm{m}$ were used for the simulation. As shown in Figure 19, the steel cable displacement under a small lateral external force is smaller than that with steel connecting rods. However, when the lateral uniform force $\mathrm{W}$ exceeded $0.409 \mathrm{kN} / \mathrm{m}$, the lateral restraint of the steel connecting rods was significantly greater than that of the cables. In addition, strong nonlinearity was observed between the resultant force and the displacement with steel connecting rods, indicating that the lateral displacement could converge to a maximum amount, and that the lateral restraint worked as expected. However, with steel cables, the lateral uniform force $\mathrm{W}$ exhibits a linear relationship with the lateral displacement when $W<1.022 \mathrm{kN} / \mathrm{m}$.

Considering that the steel connecting rods were prone to buckling owing to their high slenderness ratio, the effect of changing the arrangement of the cables used for lateral restraint is discussed below. For the simulation, the lateral uniform force $W$ was chosen to be $1.022 \mathrm{kN} / \mathrm{m}$, and three arrangements were considered, as shown in Figure 20. The first was the original arrangement of the steel connecting rods. The second maintained the original connection points between the steel connecting rods while changing the configuration from the original crossovers to vertical parallel lines perpendicular to the bridge deck. Hence, the number of cables was reduced from 44 to 38 , and the spacing between adjacent connection points was five spans of the transverse beams.

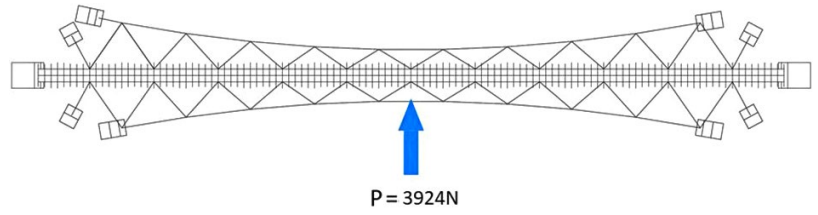

Figure 17. Lateral force $P$ acting on central node of bridge deck

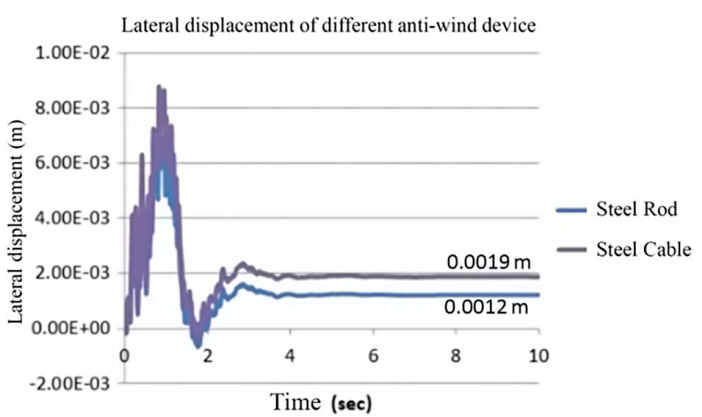

Figure 18. Lateral force $P$ acting on central node of bridge deck

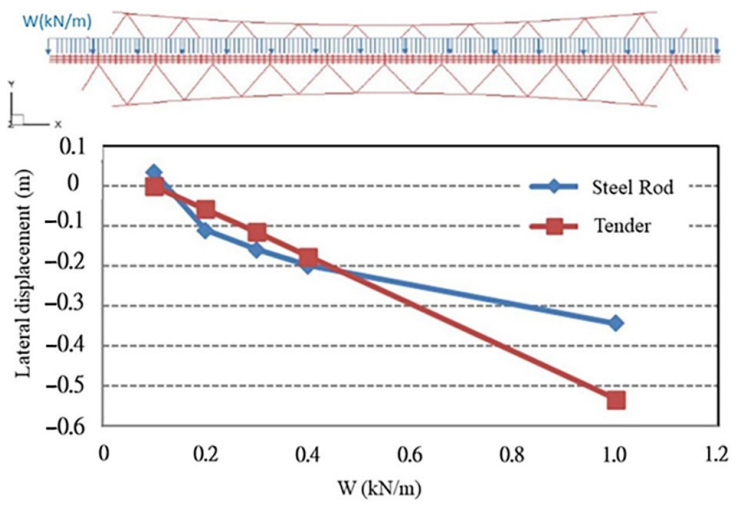

Figure 19. Comparison of different lateral forces $P$ and transverse displacement with two configurations

The third used even fewer vertical parallel lines, reducing the number of cables further from 38 to 18 . The results of the analysis are presented in Figures 21 and 22. As shown in these two figures, only the dead load was applied in the initial stage from 0 to $10 \mathrm{~s}$, and the wind load acted after $10 \mathrm{~s}$. Figure 21 presents the result for the case without damping $(c=0)$, and Figure 22 for $c=1.0$. To obtain an appropriate damping coefficient in the dynamic response, several damping values $(0-2.0)$ were input in the VFIFE numerical analysis. Finally, $c=1.0$ was chosen as the appropriate damping coefficient, and there was no over-damping under this condition. Only the cases where $c=0$ and $c=1.0$ are presented in this paper. The results depicted Figures 21 and 22 reveal several high-frequency particle motion responses in the case without damping. For the case without damping (Figure 21), the dynamic maximum displacement for the original, second, and third arrangements were $0.464 \mathrm{~m}, 0.479 \mathrm{~m}$, and $0.635 \mathrm{~m}$, respectively. In view of the lateral displacement resistance to the wind load, the original arrangement behaved the best with minimum dynamic displacement among the three arrangements. However, for the case $c=1.0$ (Figure 22), 
the high-frequency particle motion response disappeared, and the dynamic maximum displacements for the original, second, and third arrangements were $0.375 \mathrm{~m}, 0.430 \mathrm{~m}$, and $0.567 \mathrm{~m}$, respectively. This shows that the original arrangement also had the minimum dynamic displacement. When the analysis time was extended to $20-25 \mathrm{~s}$, the results converged to a steady state, as shown in Figure 22, and it was found that the transverse displacement with the original arrangement was $0.314 \mathrm{~m}, 0.270 \mathrm{~m}$ with the second arrangement, and $0.411 \mathrm{~m}$ with the third arrangement. From the steady-state analysis results, the best restraint on transverse displacement was achieved with the second arrangement of parallel cables. The $c=0$ and $c=$ 1.0 case results show that the original arrangement had the minimum dynamic displacement during the dynamic response process. However, in the final steady state, the second arrangement had a smaller displacement than the original and performed the best. In general, the specification of the design code in Taiwan is adopted for the

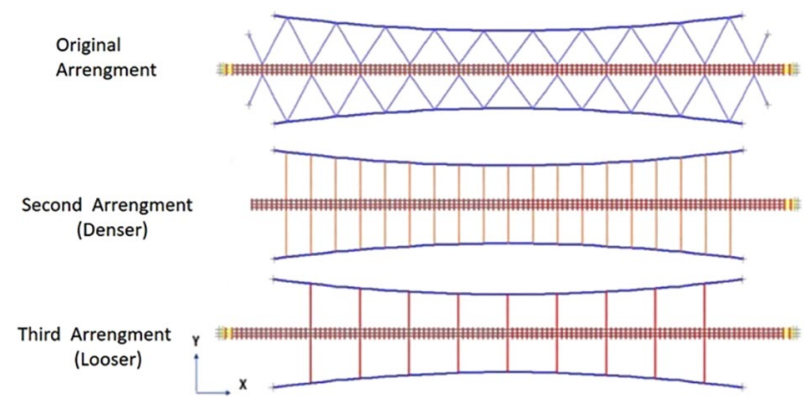

Figure 20. Three arrangements of steel cables

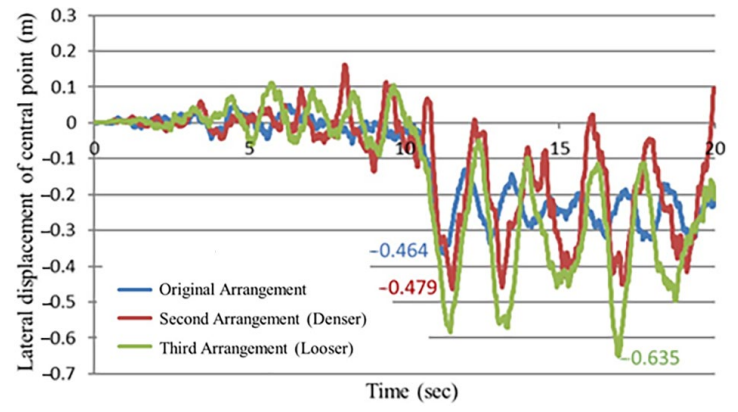

Figure 21. Comparison of analysis results with three arrangements of steel cables $(c=0)$

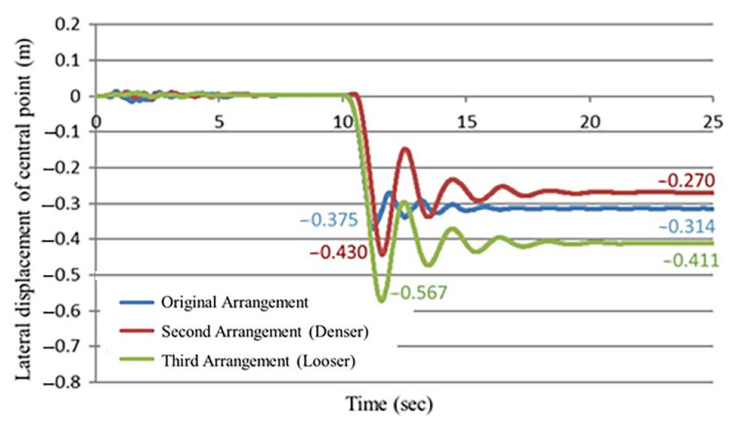

Figure 22. Comparison of analysis results with three arrangements of steel cables $(c=1.0)$ steady-state results. Therefore, without changing the spacing between the original connection points, changing the current crossover arrangement to a parallel arrangement results in better resistance to lateral wind. In the future, it is recommended that the arrangement be changed accordingly to avoid the current problem of replacing steel connecting rods owing to buckling.

\section{Conclusions and recommendations}

In this study, the slope performance analysis was performed for the abutment slopes on both sides of the suspension bridge. According to the analysis results, the safety factors of the northern slope met the general requirements, indicating that the slope system was stable. However, the safety factor of the southern slope was slightly lower than the general recommended value under normal conditions; with heavy rain and earthquakes, there is a potential for damage.

A lift-off test was performed on the ground anchor from the retaining wall on the south side of the suspension bridge. The results showed that the residual load was $49.17 \%$. The analysis results of the slope cross-section were all lower than the general recommended values under normal conditions, heavy rain and earthquakes. Therefore, the comprehensive performance evaluation results demonstrated that reinforcement should be performed on the southern slope.

The measured deflection changes of the suspension bridge were primarily because of the temperature. The changes in central deflection were less than the prealert threshold value, except for one measurement data point in December 2011, which could be an error because regular measurements were not yet in place.

The analysis of the cable internal force showed that the design forces were generally within the average of the variation in the calculated forces. The error percentage was approximately $2 \%$.

The deflection change must be adjusted using the test results of the compound coefficient of thermal expansion with a combination of steel and HDPE. This leads to $\alpha_{t}=$ $7.630 \times 10^{-6} /{ }^{\circ} \mathrm{C}$ as the final thermal coefficient of the compound.

The 3D VFIFE numerical model validated the calculated internal forces of the bridge's main cables with the original design value and modified the compound coefficient of thermal expansion. This model was used to validate the simulation central deflection of the bridge using monitoring data. The comparison results showed that the trend of the simulation curve was similar to that of the observation results; the difference in value between them was equivalent to an error percentage of approximately $0.27-0.39 \%$. The difference could be attributed to the possible influence of the live tourist load, and the wind force applied when the observation data are performed.

The performance of the steel cables on the suspension bridge was analyzed, and it was observed that the main cables exhibited stable performance without signs of loos- 
ening. Despite the rust and buckling at two locations on the supporting cables, the overall safety performance was not affected.

Owing to buckling, it is recommended that certain steel connecting rods be replaced and rust removal and maintenance be comprehensively conducted for the corroded parts of the bridge components.

The plan for improving the buckling of steel connecting rods was determined by performing analyses. According to the comparison between cases $c=0$ and $c=$ 1.0 , the original arrangement had the minimum dynamic displacement during the dynamic response process. However, in the final steady state, the second arrangement had a smaller displacement than the original arrangement and behaved the best. Based on the analysis results, changing the current crossover arrangement of steel connecting rods to a parallel arrangement of steel cables will not only result in good lateral wind resistance but also prevent subsequent situations where the steel rods need to be replaced owing to buckling.

\section{Acknowledgements}

The authors would like to thank Professor Chung-Yue Wang and Dr. Shih Kai Chen from the Center for Bridge and Railway Engineering Research (CBER) at the National Central University for their contributions to the numerical analysis; the Geotechnical Engineering Office, Public Works Department, Taipei City Government for the project funding, and Wirop Industrial Co., Ltd., San Lien Technology Corp., and Diagnostic Engineering Consultants Co., Ltd., for their assistance in developing the monitoring system for the suspension bridge.

\section{Disclosure statement}

The Authors declare this paper has not any competing financial, professional, or personal interests from other parties.

\section{References}

All-wisdom Engineering Consultants, Ltd. (2020). Final report of Baishihu Suspension Bridge structure safety assessment and maintenance design service in 2019. Geotechnical Engineering Office, Public Works Department, Taipei City Government.

Brownjohn, J., Dumanoglu, A., \& Taylor, C. (1994). Dynamic investigation of a suspension footbridge. Engineering Structures, 16(6), 395-406.

https://doi.org/10.1016/0141-0296(94)90054-X

Carpenter, J. R. (1986). STABL5/ PC STABL5 user manual (Joint Highway Research Project JHRP-86/14). School of Civil Engineering, Purdue University.

Chen, S. K. (2011). Analysis of the nonlinear behavior of bridge by the vector form intrinsic finite element method [ $\mathrm{PhD}$ thesis]. Department of Civil Engineering, National Central University, Chung-li, Taiwan.
Duan, Y. F., He, K., Zhang, H. M., Ting, E. C., Wang, C. Y., Chen, S. K., \& Wang, R. Z. (2014). Entire-process simulation of earthquake-induced collapse of a Mockup cablestayed bridge by vector form intrinsic finite element (VFIFE) Method. Advances in Structural Engineering, 17(3), 347-360. https://doi.org/10.1260/1369-4332.17.3.347

Lee, C. R. (2015). Nonlinear dynamic analysis of suspension bridge by the VFIFE method [Master's thesis]. Department of Civil Engineering, National Central University, Chung-li, Taiwan.

Ministry of Transport and Communications of the Republic of China. (2009). Code for design of highway and bridges.

Sen, P. (2018). A method of internal force estimation and dynamic analysis for suspension footbridges [Master's thesis]. Department of Civil Engineering, National Central University, Chung-li, Taiwan.

Shih, J. Y., Wang, C. Y., \& Wang, R. Z. (2012). Dynamic analysis of the vehicle-track-bridge interaction using vector form intrinsic element method. In Proceedings of the 1st International Workshop on High-Speed and Intercity Railways (pp. 249-259). Springer. https://doi.org/10.1007/978-3-642-27963-8_24

Ting, E. C., Shih, C., \& Wang, Y.-K. (2004a). Fundamentals of a vector form intrinsic finite element: Part I. Basic procedure and a plane frame element. Journal of Mechanics, 20(2), 113-122. https://doi.org/10.1017/S1727719100003336

Ting, E. C., Shih, C., \& Wang, Y.-K. (2004b). Fundamentals of a vector form intrinsic finite element: Part II. plane solid elements. Journal of Mechanics, 20(2), 123-132. https://doi.org/10.1017/S1727719100003348

Ting, E. C., Duan, Y. F., \& Wu, D. (2012). Vector mechanics of structures. China Science Publishing \& Media Ltd.

Wang, R. Z. (2005). Vector form motion analysis of structure [PhD thesis]. Department of Civil Engineering, National Central University, Chung-li, Taiwan. 